\title{
Quão Plural é o Ensino de Marketing? Um Estudo Exploratório com Professores dos Cursos de Graduação em Administração
}

\section{How Plural is the Teaching of Marketing? An Exploratory Study with Teachers of Undergraduate Business Course}

\author{
Daniel de Oliveira Barata Merabet \\ Rosana Oliveira da Silva \\ Clayton Pereira Gonçalves \\ Denise Franca Barros
}

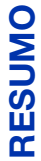

O objetivo desta pesquisa é investigar sobre quão plural é o ensino de marketing em cursos de graduação em Administração, considerando três escolas de pensamento em Marketing: a gerencial, a de macromarketing e a de marketing crítico. Para atingir tal objetivo, foram entrevistados professores de marketing em diferentes cursos de graduação em Administração no Rio de Janeiro. Os resultados apresentados nas três categorias analíticas produzidas apontam para: a) O reconhecimento de que o conteúdo programático baseado no marketing gerencial é insuficiente para atender aos desafios que cercam a prática de marketing; b) A preocupação em referenciar as práticas de marketing às demandas do mercado e; c) A importância de estabelecer discussões éticas, sociais e críticas que envolvam não somente a relação entre empresas e consumidores, mas que reconheçam o papel do Estado e as pressões da sociedade civil organizada. Os autores concluem que as abordagens de macromarketing e de marketing crítico podem contribuir para que as discussões abordadas possam ser conduzidas pelos professores, de maneira mais plural e sistematizada, para que o ensino de marketing transborde dos domínios da sala de aula para projetos de pesquisa e de extensão.

Palavras-chave: Cursos de Graduação em Administração. Ensino de Marketing. Escolas de Pensamento em Marketing.

The aim of this research is to investigate how plural the teaching of marketing is in Business undergraduate courses, considering three schools of thought in Marketing: managerial, macromarketing and critical marketing. In order to achieve this goal, marketing professors were interviewed in different Business undergraduate courses in Rio de Janeiro. The results presented in the
Recebido em: 12/12/2018 Aprovado em: 20/04/2019

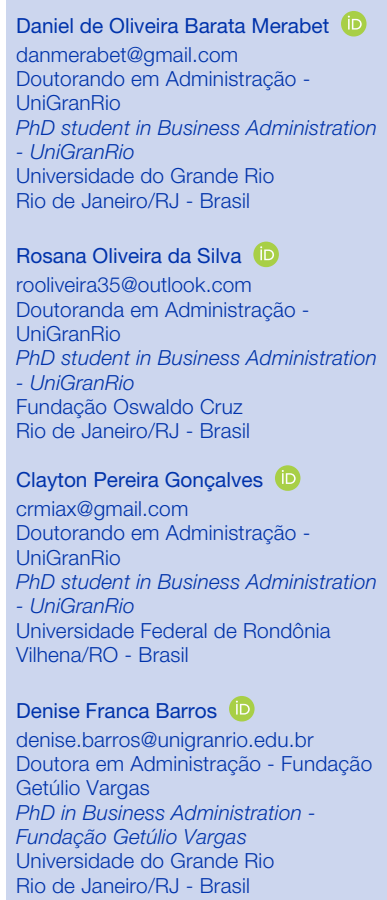


three analytical categories produced point to: a) the recognition that the programmatic content based on managerial marketing is insufficient to meet the challenges surrounding the practice of marketing; b) the concern with referring marketing practices to market demands and; c) the importance of establishing ethical, social and critical discussions that involve not only the relationship between companies and consumers, but that recognize the role of the State and pressures from organized civil society. The authors conclude that macromarketing and critical marketing approaches can contribute so that discussions can be conducted by teachers in a more plural and systematized way, so that marketing teaching spills over from the classroom domains to research and extension projects.

Keywords: Business Undergraduate Courses. Marketing Schools of Thought. Marketing Teaching.

\section{Introdução}

Marketing é uma disciplina jovem, contando com pouco mais de 100 anos, mas com tamanha popularidade e influência que parece bem mais antiga. De acordo com Jones e Monieson (1990), os EUA e a Alemanha foram as nações precursoras, incluindo marketing nos cursos de graduação no início do século XX. Em outros países, ela passou a figurar em cursos universitários somente nos anos 1960, como é o caso da Inglaterra (HACKLEY, 2009) e do Brasil (BACELLAR; IKEDA, 2011; BOSCHI, BARROS; SAUERBRONN, 2017).

Reconhecido como conhecimento de influência global (ALVESSON; WILMOTT, 1993) e importante produto de exportação para países em desenvolvimento (FARIA, 2015), o ensino de tal conhecimento é tido como importante tópico de pesquisa no exterior. Há quase 40 anos, Law e Wensley (1979) pontuavam o quão relevantes eram as discussões sobre como e o que deveria ser ensinado na disciplina, bem como reconheciam que tal importância derivava do fato que poucos cursos não incluíam a disciplina em seu rol de matérias. Bacellar e lkeda $(2007 ; 2011)$ mostram, por meio de publicações em periódicos de marketing, que a disciplina apresentou preocupação com o ensino desde seus primórdios, na primeira metade do século passado. Não à toa, Ferrell et al. (2015), bem como Shaw (2015), afirmam que a evolução da disciplina pode ser melhor entendida a partir das raízes históricas da educação de marketing. Frequentemente, pesquisas também destacam a 
importância de pesquisas históricas em marketing, para entender o marketing atual (e.g. CONEJO; WOOLISCROFT, 2018; BALMER; BURGHAUSEN, 2019).

Embora a disciplina seja muito popular no Brasil, o ensino de marketing, como objeto de estudo, não goza da mesma importância. Exceções incluem Ajzental, (2008), Bacellar e Ikeda (2007; 2011), Falcão (2014), Oliveira, Lourenço e Castro (2015), Boschi, Barros e Sauerbronn (2017), Salvador e Ikeda (2019), entre poucos outros. Tal fato é problemático não apenas por encobrir o papel ideológico da disciplina, como bem aponta Patsiaouras (2019), mas também por permitir que conceitos criados e ensinados em um contexto de até um século atrás continuem a ser ensinados exatamente da mesma maneira (FERRELL et al., 2015), como se fossem ahistóricos e universais. Essa é uma constatação que parece se estender para os cursos de Administração, que além de não considerarem a realidade brasileira (OLIVEIRA; LOURENÇO; CASTRO, 2015; VASCONCELOS; COSTA; CARVALHO, 2016), não acompanham as mudanças e promovem "[...]uma reprodução técnica e instrumental desassociada da formação de pensadores críticos e criativos" (BOAVENTURA et al., 2018, p.1). Justen e Gurgel (2015, p. 867) adicionam que "[...]há um problema na base da formação em Administração, o qual desconsidera elementos históricos da constituição do Estado e do setor privado no Brasil e no mundo".

No que se refere ao ensino de marketing, a evolução histórica da disciplina também nos mostra que o que se chama de conhecimento em marketing hoje é um determinado cânon (WITKOWSKI, 2005), que assumiu caráter disciplinar, deixando abordagens e respectivas temáticas à margem, como, por exemplo, Macromarketing (SHAW; JONES, 2005) e Marketing Crítico (TADAJEWSKI, 2010). Vários autores mostram que o marketing gerencial foi assumindo o protagonismo da disciplina a partir da Guerra Fria (WITKOWSKI, 2005), a tal ponto que hoje a abordagem gerencial seja tão pervasiva e dominante (LAYTON; GROSSBART, 2006) que marketing seja considerado quase sinônimo dos famosos 4 Ps. O acirramento dos processos de globalização, ao longo da década de 1990, também favoreceu a ideia de que o desenvolvimento dos países estaria baseado em economias de mercado, pavimentando caminho para que o conhecimento de marketing gerencial fosse ainda mais difundido e aplicado do que questionado (FARIA, 2015).

Originalmente uma disciplina preocupada com vários outros aspectos das relações de mercado (WILKIE; MOORE, 2006; LAYTON; GROSSBART, 2006), 
marketing passa a desconsiderar questões que extrapolam a relação entre comprador/vendedor, o foco central do marketing gerencial. Desta forma, problemas causados pelas atividades de mercado, que apontam para a necessidade de políticas públicas e/ou regulação (REDMOND, 2018), passariam despercebidos. A literatura de marketing reporta tal discussão, tal como a dicotomia micro versus macro. Os assuntos relativos às relações entre atividades mercadológicas e a sociedade eram reconhecidas do domínio do macromarketing, enquanto o domínio do micromarketing passou a ser visto não mais como subárea, mas como a própria disciplina, marketing.

Ao longo do tempo, questões relativas à ética nos negócios, globalização, problemas de mercado, desenvolvimento e até mesmo os problemas causados pelas atividades mercadológicas, passaram a figurar em uma outra abordagem da disciplina, além da de Macromarketing. A virada crítica ocorrida nos anos 1990, que deu origem à subárea conhecida como Critical Management Studies (ALVESSON; WILMOTT, 1993), foi mais evidente nos estudos organizacionais, mas também influenciou, embora em menor grau, a academia de marketing, culminando no que ficou conhecido como Marketing Crítico. Para Tadajewski (2011), uma das razões era a de que marketing era a disciplina com menos autocrítica e equiparada às práticas voltadas a vender mercadorias às pessoas.

Marketing crítico compreende pesquisas que questionam o discurso disciplinar que constitui e tem origem em uma ordem cultural específica, que também inclui as dimensões políticas, econômicas e sociais, de organização da vida humana (TADAJEWSKI, 2010). Tadajewski (2011) aponta que a primeira publicação do termo marketing crítico aconteceu no Journal of Marketing, aliando-se a uma gama de abordagens teóricas críticas sociais, tais como Marxismo, Teoria Crítica, vertentes Feministas, abordagens Pós-Coloniais, entre outras.

No Brasil, a abordagem gerencial segue predominante na academia de marketing, tanto no âmbito das publicações em periódicos e congressos (SCUSSEL, 2017), quanto na formação de pesquisadores e professores nos cursos de pós-graduação stricto sensu (VELUDO-DE-OLIVEIRA; QUINTÃO; URDAN, 2014). Isto sugere que outras abordagens de marketing, tais como Macromarketing e Marketing Crítico, não alcançariam à contento, o ensino de marketing ao nível da graduação, mesmo já havendo o reconhecimento, por parte de docentes, acerca 
das limitações da abordagem gerencial em lidar com questões éticas, sociais e de políticas públicas que cercam as práticas de marketing no contexto brasileiro (BERARDINELLI; SAUERBRONN, 2017; ENGLERT et al., 2018).

Ao adotar o escopo (reduzido) da Escola de Pensamento do Marketing Gerencial e empurrar para as margens assuntos inerentes à formação e ao funcionamento dos mercados, como regulação, políticas públicas, papel dos governos, a disciplina perde importância e capacidade de aplicação por praticantes. Tal questão é, especialmente, problemática se pensarmos na formação dos profissionais de Administração e suas subáreas. Ao travarem contato tão somente com a dimensão micro, que privilegia as decisões gerenciais, desconsiderando a total extensão e importância de fenômenos e entes de mercado que não a unidade "firma", os futuros profissionais podem tornar-se meio de reprodução de tal visão reducionista. Considerando que o curso de Administração tem o maior número de ingressantes anuais, com enorme volume de formandos, no entanto, tal sucesso obscurece limitações na qualidade da formação dos profissionais, conforme apontam Souza, Gehrard e Brito (2018). Assim, é mister lidar com problemas de conteúdo e ensino que possam, de alguma forma, limitar as competências dos futuros administradores. Da mesma forma, tal discussão pode contribuir para um relevante setor de negócios que é, atualmente, a educação superior, como apontam Salvá, Bauer e Wanderley (2019).

A partir de tal contexto, o objetivo desta pesquisa é investigar sobre quão plural é o ensino de marketing no nível da graduação dos cursos de Administração, considerando três escolas de pensamento: a gerencial, a de macromarketing e a de marketing crítico. Para a atingir tal objetivo, os autores entrevistaram professores de marketing em cursos de graduação em Administração no Rio de Janeiro. Centramos nosso suporte teórico na evolução e difusão histórica do conhecimento em Marketing e em pesquisas sobre o ensino da disciplina. Tal articulação teórica nos permitiu criar as categorias analíticas que apontam para: a) O reconhecimento de que o conteúdo programático baseado no marketing gerencial é insuficiente para atender aos desafios que cercam a prática de marketing; b) A preocupação em referenciar as práticas de marketing às demandas do mercado e; c) $A$ importância de estabelecer discussões éticas, sociais e críticas que envolvam não somente a relação entre empresas e consumidores, mas que incluam o papel do Estado e as pressões da 
sociedade civil organizada. Este artigo, que é parte de um projeto mais amplo sobre a história e prática de educação de marketing, encerra apresentando os resultados a partir de três categorias e discutindo possibilidades de pesquisas futuras.

\section{Pluralidade de Pensamento em Marketing: um Breve Resgate Histórico}

A consolidação da escola de pensamento gerencial em marketing nas décadas de 1950 a 1970 (WILKIE; MOORE, 2003; SHAW; JONES, 2005; ELLIS et al., 2011) contribuiu para deslocar para a margem outras possibilidades epistemológicas e paradigmáticas de investigação e reflexão científica (ARNDT, 1985). Naquele momento, dois discursos disputavam os rumos futuros da academia de marketing norte-americana (HUNT, 1976): o primeiro, baseado em uma abordagem que privilegiava o relacionamento entre firma e consumidor, portanto, de dimensão micro (KOTLER, 1979); e o segundo, que expandia a dimensão micro considerando outras organizações do sistema social (ARNDT, 1978). Para os que defendiam os pressupostos do primeiro, não se fazia necessário problematizar práticas de marketing em territórios da administração pública e do terceiro setor, pois o que era praticado em organizações privadas também poderia ser reproduzido nas organizações desses domínios, mesmo com natureza e propósitos distintos (KOTLER, 1979).

A guinada da academia de marketing ao pensamento gerencial representa, de certa forma, um distanciamento de preocupações que cercavam a constituição do campo nos seus primórdios (WILKIE; MOORE, 2006). Não eram raros os debates sobre os impactos das atividades de marketing na sociedade, como adequação dos canais de distribuição às demandas locais (ANDERSON, 1936), e a elaboração de políticas públicas sobre as consequências das falhas de mercado (NASON, 1989) - debates existentes na atualidade (e.g. DUFFY; LAYTON, 2015; PEREIRA, 2016; KLEIN, 2019; REDMOND, 2018; SILVA, 2018). Ao privilegiar a geração de conhecimento para um praticante específico, o gerente da grande empresa, diversos atores foram obscurecidos (LAYTON; GROSSBART, 2006). Esse movimento histórico também provoca efeitos sobre as abordagens teóricas e metodológicas utilizadas por pesquisadores de marketing que adotaram os pressupostos da teoria 
econômica neoclássica para definir o que é mercado e quem são seus principais atores (VENKATESH; PENÃLOZA, 2006). Isso influenciou a forma como marketing deveria ser praticado e conteve o avanço das contribuições oriundas da sociologia, antropologia e ciências política (ARNDT, 1985; SHAW; JONES, 2005; HACKLEY, 2009) e o reconhecimento da necessidade de aproximar a disciplina e o ensino, do mercado em sua concepção mais ampla (FLEMING et al., 2015).

Ao contrário do se poderia imaginar, o conhecimento de marketing produzido pela escola gerencial promoveu maior distanciamento do que aproximação dos praticantes (BAKER; SAREN, 2010). Em parte, isso pode ser explicado pelos esforços empreendidos na década de 1960 em elevar o status científico não só de marketing, como da ciência produzida nas escolas de negócio (HACKLEY, 2009). Tomando o Journal of Marketing como exemplo, é possível observar o recrudescimento dos métodos quantitativos de pesquisa, e seus respectivos modelos analíticos, e a redução da participação de praticantes vinculados a diversas esferas da sociedade em prol de acadêmicos treinados (WILKIE; MOORE, 2003). Também é válido lembrar sobre o contexto que cercava os EUA nesta época, que conferia ao conhecimento científico, matrizes ideológicas pró-mercado (FARIA, 2015).

Embora à margem, as perspectivas associadas às dimensões distintas da gerencial foram devidamente estabelecidas, em termos institucionais, com a criação de alguns periódicos, tais como o Journal of Consumer Research (1974), o Journal of Macromarketing (1981) e o Journal of Public Policy and Marketing (1982). A escola de pensamento de macromarketing, ao contrário da abordagem gerencial, se estabelece justamente por sua pluralidade, abrigando algumas temáticas, tais como sustentabilidade, qualidade de vida, ética e justiça distributiva, sistemas de marketing, desenvolvimento e história do marketing (SHAPIRO, 2015).

Pontua-se que, particularmente, os estudos de macromarketing são caracterizados pela tensão existente entre os sistemas de marketing (LAYTON, 2019) e seus efeitos sobre a sociedade (DOMEGAN et al., 2019). Sob esta perspectiva, alguns atores, tal como governo, são alçados à condição de protagonistas (e.g. SILVA; BARROS; GOUVEIA, 2017; FERREIRA; BARROS, 2018). Isso não significa uma total ruptura com a escola gerencial de marketing, mas compreender os problemas decorrentes das práticas de mercado e de marketing, que podem produzir consequências indesejadas (NASON, 1989; ERTEKIN; ATIK, 2015). 
Wilkie e Moore (2003) lembram, por exemplo, que na época em que macromarketing emergiu na década de 1970 nos EUA, muitas críticas eram destinadas às práticas de marketing e aos excessos cometidos por empresas, o que favoreceu debates no âmbito da ética (BACELLAR; IKEDA, 2011). Nos anos 1980, a disciplina buscou consolidar a natureza e escopo das pesquisas que enquadravam fenômenos de marketing a partir desta concepção. Já a partir dos anos 1990, os efeitos recíprocos entre marketing e globalização passaram a ser problematizados em termos sociais, econômicos, ambientais e de consumo.

Ainda na década de 1990, foi possível notar críticas não somente às práticas de marketing e aos abusos das grandes corporações, mas também ao conhecimento em gestão difundido pelas escolas de negócio, tido como universal a partir dos EUA (FARIA, 2015). Isso se torna mais evidente com o movimento dos estudos críticos gerenciais que não somente apontam para as limitações de natureza epistemológica do paradigma positivista-funcionalista, que constitui o mainstream da academia de Administração, como assegura a importância de outras tradições teóricas (DAVEL; ALCADIPANI, 2003). No que tange à marketing, tem-se o marketing crítico.

Não se trata de um movimento unificado ou singular, mas um domínio acadêmico marcado por distintas formas de engajamento (SAREN, 2009). Contudo, comum aos pesquisadores críticos, está a identificação dos obstáculos que impedem aquilo que a sociedade deveria ser em termos de convivência harmoniosa entre indivíduos e instituições. De forma mais específica, estudos críticos em marketing oferecem uma oportunidade para analisar o relacionamento entre marketing e sociedade (SCHROEDER, 2007) a partir de alguns temas, tais como boicote ao consumo, crítica ao mainstream do marketing, cultura de consumo, ensino e pesquisa em marketing, ética, gênero, indivíduo e consumo, macromarketing, marketing social, minorias, poder e ideologia, sociedade de consumo e teoria de marketing (MARANHÃO; PAES de PAULA, 2012). Teklehaimanot et al. (2017), por exemplo, fazem uma tentativa de inserir uma outra perspectiva para o estudo e ensino de marketing que se afasta da abordagem gerencial: o marketing social.

Tadajewski (2010) argumenta sobre a importância da inclusão dos estudos críticos em marketing, de forma a contrabalançar a influência da abordagem hegemônica da disciplina no ensino. Para o autor, a reflexão dos alunos quanto às 
consequências das práticas de marketing na sociedade, tenderiam a torná-las mais "justas", tendo por "justas" as condições apresentadas por diferentes tradições críticas, geralmente ligadas a projetos de emancipação do indivíduo. Viana, Costa e Brito (2016) e Bevilacqua e Medeiros (2019) também buscaram contribuir com novas possibilidades de estudos críticos para o conhecimento de marketing. Mas, ainda assim, vale lembrar que a constituição do marketing crítico também possui contornos etnocêntricos (DINIZ et al., 2016).

Segundo Faria (2015), a disciplina de marketing é oferecida nos cursos de Administração no Brasil de forma acrítica. De certa forma, isso reflete a postura de pesquisadores brasileiros em reproduzir tal conhecimento sem a devida contextualização à realidade brasileira (VIEIRA, 2003), nem de entender os efeitos ideológicos associados ao lócus de enunciação que concede à academia norte-americana autoridade científica e epistemológica sobre um certo tipo de marketing que estabelece: a) O mercado como abstração impessoal e autônoma capaz de atender de forma racional os interesses dos produtores e consumidores, tidos como principais agentes desta esfera e; b) Técnicas funcionais e orientações estratégicas que privilegiam a prática de marketing a partir da visão do profissional de empresas que visa aprimorar a dimensão econômica de seus resultados. Esse tipo de marketing, que desloca o olhar atento para suas dimensões ideológicas, pode influenciar as escoIhas dos professores na delimitação do conteúdo da disciplina e na forma com que esta realidade é apresentada ao aluno. Se, de fato, isto ocorrer, poder-se-ia dizer que a reprodução do conhecimento científico na academia brasileira de marketing também possui engrenagem semelhante na dimensão do ensino, o que pode ser considerado problemático em termos pedagógicos, sociais e profissionais. Parte do problema pode ser a dificuldade da área de lidar com sua própria história. Jones e Shaw (2018) e Shaw (2015) afirmam que os estudantes de pós-graduação não conhecem a história da disciplina, em grande parte, porque seus professores não os expuseram a ela e, portanto, tais discussões não são comuns na literatura de marketing (HEMAIS, 2019).

No Brasil, os estudos críticos ainda não tiveram grande repercussão na área de marketing (MARANHÃO; PAES de PAULA, 2012; ITUASSU et al., 2015), quando comparado, por exemplo, à área de estudos organizacionais (FARIA; GUEDES, 2005). De certa forma, isto é reflexo da posição marginal que a perspectiva crítica 
em marketing também ocupa na academia internacional em decorrência da concepção hegemônica de marketing, vinculada ao aprimoramento de questões gerenciais. Porém, os efeitos agregados mais amplos gerados na sociedade, em decorrência desta abordagem hegemônica são largamente desconsiderados. Situação semelhante ocorre com as temáticas que encontram abrigo na abordagem de macromarketing, que conta com poucos trabalhos publicados em território brasileiro (SCUSSEL, 2017; BERARDINELLI; SAUERBRONN, 2017). É justamente esta lacuna que ajuda a tornar relevante a aproximação dessas duas abordagens ao marketing gerencial, por meio de práticas de ensino, uma vez que possui o potencial para formar profissionais que empreendam o exercício mais reflexivo sobre as consequências de suas práticas em diferentes organizações (públicas, privadas ou do terceiro setor) e sociedades (desenvolvidas ou em desenvolvimento).

\section{Ensino de Marketing}

Como mencionado, o paradigma dominante em marketing foi constituído por mecanismos de legitimação instaurados ao longo do último século nos EUA (WILKIE; MOORE, 2003). Tal paradigma defende a ideia de que as trocas empreendidas no mercado geram inexoravelmente benefícios para sociedade e evidenciam a busca da disciplina por status de ciência fundamentada nos pressupostos do positivismo e do funcionalismo (ELLIS et al., 2011). A aproximação da área com as abordagens de marketing crítico e de macromarketing ajudaria a desvelar as bases do paradigma dominante destacando: a) A análise crítica da construção do marketing como discurso acadêmico e; b) Compreensão das consequências das práticas de marketing na sociedade. Quais seriam os desdobramentos dessa aproximação no âmbito do ensino da disciplina?

Discussões sobre o ensino de marketing datam desde os primeiros momentos da constituição da disciplina nos EUA (HAGERTY, 1936) e no Brasil (GUAGLIARDI, 1983). É válido ressaltar que temas ligados a macromarketing assumiam papel de destaque no escopo sobre o que deveria ser ensinado em marketing no contexto brasileiro na década de 1980 (GUAGLIARDI, 1983), ao contrário do que se observa nos dias atuais, com o predomínio da perspectiva gerencial e da literatura estran- 
geira, tanto no âmbito da graduação (BACELLAR; IKEDA, 2007) como na pós-graduação (VELUDO-DE-OLIVEIRA; QUINTÃO; URDAN, 2014).

Também vale destacar que a perspectiva gerencial se mostrou problemática na dimensão do ensino, justamente por ter dificuldades em elucidar a prática de marketing. Bacellar e Ikeda (2007) realizaram um estudo sobre o ensino de marketing a partir da perspectiva dos professores e mostraram as dificuldades que professores enfrentavam para lidar com essa questão, sem mencionar os constantes desafios e o ceticismo apresentados pelos alunos. Para enriquecer este cenário também é válido lembrar que os professores mediam o relacionamento de ensino e aprendizagem com seus alunos sob pena de serem mal avaliados (IKEDA; BACELLAR, 2008). Posto esse cenário, como pode o docente arriscar abordagens alternativas ao marketing gerencial, como macromarketing e marketing crítico?

Paes de Paula e Rodrigues (2006) relataram a experiência em conduzir uma disciplina da área de estudos organizacionais, com claras orientações críticas em um curso de pós-graduação. Em destaque, o trabalho aponta para o sentimento de desconforto e frustração tanto para os professores quanto para os alunos. Ainda assim, os autores defendem a importância deste tipo de iniciativa, uma vez que as abordagens tradicionais de ensino também passam por uma crise de relevância.

Embora escassas, existem experiências de condução de disciplinas de marketing com a utilização de abordagens alternativas. Schroeder (2007) explorou junto a vários professores de marketing se eles mantinham uma postura crítica tanto em relação à prática quanto à abordagem dos conteúdos da disciplina. Em suas considerações apontou para quatro implicações decorrentes de sua pesquisa: o pluralismo (inexistência de uma única definição verdadeira de marketing crítico); o foco em questões sociais (sugerindo relação com macromarketing); a reflexividade do pesquisador; e a interdisciplinaridade. No que tange ao ensino de marketing crítico e a sua inclusão no conteúdo das disciplinas de marketing, o autor alerta sobre os perigos da crítica pela crítica, recomendando que seja dada mais ênfase à reflexão e análise a partir dessa perspectiva. Contudo, longe de uma perspectiva ingênua, o autor também alerta para os riscos que o professor teria ao mobilizar esse conhecimento, tendo em vista o ethos da instituição em que trabalha e as expectativas previamente existentes dos alunos em relação à disciplina. Radford, Hunt e Andrus (2015) advertem que o ensino de marketing gerencial na gradua- 
ção, que prioriza a abordagem micro em detrimento da macro, não seria capaz de desenvolver nos alunos capacidade para transitar em dimensões do mercado que demandariam decisões mais políticas, sociais e éticas que econômicas.

As possibilidades da reflexão crítica como parte integrante do conteúdo das disciplinas de marketing, bem como os problemas de implementação em sala de aula nos cursos de graduação e pós-graduação, foram explorados por Catterall, Maclaran e Stevens (2002). Os autores apontam para duas direções: a) O fato de a orientação gerencial ignorar questões políticas e morais que cercam a função gerencial e; b) O foco tecnocrático que enfatiza "o que" e "como" as práticas de marketing falham em retratar as reais condições de incerteza e complexidade enfrentadas pelos profissionais.

Tregear et al. (2010) investigaram a visão, percepção e experiência de docentes sobre aplicação de abordagens críticas de marketing na graduação. Os autores identificaram quatro abordagens críticas: 1. Ênfase na indústria: consiste em encorajar os estudantes à reflexão sobre o relacionamento entre marketing e sociedade; 2. Ênfase externa: consiste em encorajar os estudantes a adotarem uma postura questionadora e desafiadora em relação ao material da disciplina (livros, artigos, casos); 3. Ênfase acadêmica: consiste em introduzir os estudantes à perspectiva da teoria crítica para analisar tópicos de marketing e; 4. Ênfase no estudante: consiste em oferecer aos estudantes a oportunidade de "aprender fazendo" (simulação de jogos ou trabalhos de disciplina). Na pesquisa, os autores encontraram os tipos mais frequentes relatados pelos entrevistados 1 e o 4, mostrando que talvez exista espaço para discussões baseadas em pedagogias críticas.

No Brasil, entre poucos estudos realizados sobre o tema, encontra-se o de Maranhão, Motta e Leitão (2006) que investigaram as possibilidades de introdução de ensino de marketing crítico por meio de um modelo positivista. Embora os autores não tenham problematizado o papel da crítica e suas correspondentes tradições, buscam uma maneira de instaurar a discussão na academia brasileira de marketing, levantando questões sobre a formação de professores, a escassez de material específico (artigos) para viabilizar as atividades e a necessidade de contemplar diversas perspectivas para observar os fenômenos de marketing. Ainda assim, existem alguns trabalhos que indicam benefícios da inclusão de conteúdos ligados à marketing para a formação do Administrador, mostrando a importância dada à disciplina (e.g. BARBOZA; SILVA, 2019). 
Com base na revisão de literatura apresentada, apresenta-se o Quadro 1, onde são comparadas as diferentes concepções sobre as práticas de marketing, perspectiva a serem adotadas e o que deve ser ensinado em função das ênfases tradicional, social e crítica adotadas nos currículos da disciplina e, que, respectivamente, estão ligadas às abordagens de marketing gerencial, de macromarketing e de marketing crítico.

Quadro 1 Comparação entre as ênfases em currículos tradicionais e críticos em disciplinas de marketing.

\begin{tabular}{|c|c|c|c|}
\hline & Ênfase Tradicional & Ênfase "Social" & Ênfase Crítica \\
\hline  & $\begin{array}{l}\text { Marketing como } \\
\text { função gerencial da } \\
\text { firma. }\end{array}$ & $\begin{array}{l}\text { Prática de Marketing pressu- } \\
\text { põe a interrelação entre diver- } \\
\text { sos atores que compõem os } \\
\text { Sistemas de Marketing. }\end{array}$ & $\begin{array}{l}\text { Gerentes praticam } \\
\text { marketing em um amplo } \\
\text { contexto social, cultural } \\
\text { e histórico. }\end{array}$ \\
\hline 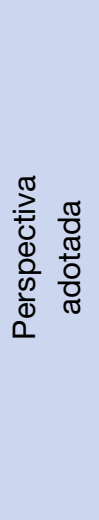 & $\begin{array}{l}\text { Marketing estudado } \\
\text { a partir de uma pers- } \\
\text { pectiva centrada no } \\
\text { relacionamento entre } \\
\text { firma e consumidor. }\end{array}$ & $\begin{array}{l}\text { Marketing estudado a partir } \\
\text { da perspectiva dos Sistemas } \\
\text { Marketing, que reconhece a } \\
\text { participação, direta ou indireta, } \\
\text { de uma rede composta por } \\
\text { diversos atores, cuja atuação } \\
\text { tanto individual como em gru- } \\
\text { po, produz impactos positivos } \\
\text { ou negativos ao ofertar bens e } \\
\text { serviços para a sociedade. }\end{array}$ & $\begin{array}{l}\text { Marketing estudado } \\
\text { a partir de múltiplas } \\
\text { perspectivas que con- } \\
\text { templam as dimensões } \\
\text { éticas, sociais e de polí- } \\
\text { ticas públicas. }\end{array}$ \\
\hline 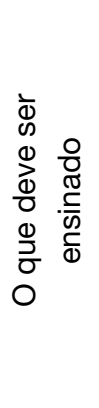 & $\begin{array}{l}\text { Os conceitos e as téc- } \\
\text { nicas de marketing, } \\
\text { tais como segmenta- } \\
\text { ção, posicionamento } \\
\text { e gestão do composto } \\
\text { mercadológico (4Ps), } \\
\text { precisam ser aprendi- } \\
\text { dos pelos alunos. }\end{array}$ & $\begin{array}{l}\text { Os conceitos e as técnicas de } \\
\text { marketing também precisam } \\
\text { ser aprendidos e podem, em } \\
\text { algum grau, ser problematiza- } \\
\text { dos a partir, por exemplo, da } \\
\text { atuação governamental. }\end{array}$ & $\begin{array}{l}\text { Os conceitos e as } \\
\text { técnicas de marketing } \\
\text { precisam ser proble- } \\
\text { matizados, uma vez } \\
\text { destacados os seus } \\
\text { contornos ideológicos, } \\
\text { históricos, culturais e } \\
\text { geopolíticos. }\end{array}$ \\
\hline
\end{tabular}

Fonte: Elaborado pelos autores, a partir de Guagliardi (1983), Catterall, Maclaran e Stevens (2002), Wilkie e Moore (2003; 2006) e Berardinelli e Sauerbronn (2017). 


\section{Percurso Metodológico}

O desenho desta pesquisa foi concebido com base em uma abordagem qualitativa. Parte de um projeto mais extenso sobre práticas de ensino de marketing ao nível da graduação e da pós-graduação, esse primeiro esforço visa, a partir de uma perspectiva exploratória, investigar sobre quão plural é o ensino de marketing ao nível da graduação dos cursos de Administração, considerando três escolas de pensamento: a gerencial, a de macromarketing e a de marketing crítico.

A partir de uma ontologia relativista, que entende que não há uma realidade única a ser capturada pelos métodos científicos, mas diversas perspectivas sobre o fenômeno sob investigação, e de uma epistemologia baseada no construtivismo social, em que indivíduos atribuem diferentes significados à realidade com base em suas próprias experiências sociais (EASTERBY-SMITH et al., 2015), foram realizadas entrevistas guiadas por roteiro semiestruturado (RICHARDSON, 2017) com professores de marketing de instituições públicas e privadas. As perguntas orientadoras do roteiro estavam divididas em dois blocos.

A primeira parte estava voltada para obtenção de informações sobre a formação acadêmica e experiências profissionais e de docência. Os dados obtidos com a aplicação desta parte do roteiro ainda foram subsidiados com as informações presentes nos currículos lattes dos entrevistados. Já a segunda parte tinha por objetivo explorar algumas questões, tais como a contribuição de marketing para a formação do administrador; sobre o que consideravam ser um competente profissional de marketing; sobre a adequação do conteúdo programático, do plano de ensino, das metodologias e experiências que apoiavam o ato de ensinar; sobre a percepção se a natureza da disciplina de marketing atende mais aos requisitos do mercado ou da academia e; sobre a importância das temáticas sociais e críticas que cercam a práticas de marketing. Importante ressaltar que, à medida que os entrevistados relatavam suas experiências, perguntas não previstas pelo roteiro foram feitas pelos pesquisadores para assegurar maior clareza e precisão acerca dos dados coletados.

Nesta etapa inicial do projeto, foram entrevistados 9 (nove) professores de marketing em IESs públicas e privadas situadas no estado do Rio de Janeiro. A ideia nesta primeira seleção de sujeitos de pesquisa foi priorizar professores com 
experiência na área (mínimo de 5 anos ensinando em cursos de graduação). Outro ponto considerado importante era entrevistar professores de instituições distintas (faculdade ou universidade, instituição pública ou privada, considerada "de elite" ou "popular", com curso avaliado com notas altas/baixas no ENADE, de pequeno/médio ou de grande porte com relação ao tamanho do alunado). A diversidade de instituições foi considerada relevante para conhecer o conteúdo e a forma de ensino de marketing, que é utilizada em instituições de natureza e características diferentes. $A$ maioria dos entrevistados começou a carreira de professor na área de marketing e quase que a totalidade dos professores tem graduação em Administração. O nível de escolaridade mínimo dos professores entrevistados é de Mestrado, sendo a metade já com curso concluído ou ainda cursando o Doutorado.

Considerações sobre a formação acadêmica também merecem destaque. Os programas de Mestrado/Doutorado cursados pelos entrevistados indicam diversidade, incluindo instituições públicas, confessionais e privadas. É importante ressaltar que não foi considerado prioritário que os professores entrevistados tivessem tal escolaridade, mas as próprias escolas hoje exigem e/ou estimulam que seu corpo docente tenha título de Doutor ou que os profissionais tenham este objetivo em seu horizonte, como alguns dos entrevistados mencionaram. O Quadro 2 apresenta a formação acadêmica dos professores entrevistados, que revela trajetórias distintas tanto em relação aos cursos de bacharelado e de stricto sensu, quanto às instituições de ensino que os abrigavam. A diversidade, no que tange à formação, além de reduzir viés de pesquisa atende aos pressupostos ontológicos e epistemológicos já apresentados. 
Quadro 2 Formação acadêmica dos docentes entrevistados.

\begin{tabular}{|c|c|c|c|}
\hline $\begin{array}{l}\text { Docentes } \\
\text { entrevistados }\end{array}$ & Formação acadêmica & $\begin{array}{l}\text { Tempo de } \\
\text { Docência }\end{array}$ & $\begin{array}{l}\text { Instituição(ões) } \\
\text { de Ensino onde } \\
\text { leciona }\end{array}$ \\
\hline 1 & $\begin{array}{l}\text { Mestrado e Graduação em Administração } \\
\text { (cursados em instituição confessional). }\end{array}$ & 5 anos & Privada \\
\hline 2 & $\begin{array}{l}\text { Doutorado e Mestrado em Administração } \\
\text { (cursados em distintas instituições privadas). } \\
\text { Graduação em Letras (cursado em institui- } \\
\text { ção pública) e em Comunicação Social (cur- } \\
\text { sado em instituição privada). }\end{array}$ & 11 anos & $\begin{array}{l}\text { Pública e } \\
\text { Privada }\end{array}$ \\
\hline 3 & $\begin{array}{l}\text { Doutorado, Mestrado (cursados na mesma } \\
\text { instituição pública) e Graduação em Admi- } \\
\text { nistração (cursado em instituição privada). }\end{array}$ & 18 anos & Privada \\
\hline 4 & $\begin{array}{l}\text { Mestrado e Graduação em Administração } \\
\text { (cursados em distintas instituições privadas). }\end{array}$ & 4 anos & Privada \\
\hline 5 & $\begin{array}{l}\text { Doutorado (cursado em instituição pública) } \\
\text { e Graduação em Administração (cursado em } \\
\text { instituição privada). }\end{array}$ & 3 anos & Privada \\
\hline 6 & $\begin{array}{l}\text { Doutorado e Mestrado (cursado em institui- } \\
\text { ção privada) e Graduação em Administração } \\
\text { (cursado em instituição confessional). }\end{array}$ & 14 anos & Pública \\
\hline 7 & $\begin{array}{l}\text { Mestrado e Graduação em Administração } \\
\text { (cursados em distintas instituições privadas). }\end{array}$ & 15 anos & Privada \\
\hline 8 & $\begin{array}{l}\text { Doutorado em Engenharia (cursado em insti- } \\
\text { tuição pública) e em Processamento de Da- } \\
\text { dos (cursado em instituição internacional), } \\
\text { Mestrado em Administração (cursado em } \\
\text { instituição privada) e Graduação em Tecno- } \\
\text { logia de Processamento de Dados (cursado } \\
\text { em instituição privada). }\end{array}$ & 16 anos & $\begin{array}{l}\text { Pública e } \\
\text { Privada }\end{array}$ \\
\hline 9 & $\begin{array}{l}\text { Doutorado (cursado em instituição privada) } \\
\text { e Mestrado em Administração (cursado em } \\
\text { instituição confessional) e Graduação em } \\
\text { Engenharia (cursado em instituição confes- } \\
\text { sional). }\end{array}$ & 15 anos & Privada \\
\hline
\end{tabular}

Fonte: Elaborado pelos autores. 
Os dados obtidos, principalmente em decorrência da aplicação da segunda parte do roteiro, permitiram aos pesquisadores acessar os modos de representação de mundo dos entrevistados ou, de forma mais específica, os discursos dos entrevistados foram entendidos como forma de acessar práticas sociais (WODAK; MEYER, 2015; ROGERS, 2017; SILVA; GONÇALVES, 2017) relacionadas ao ensino de marketing. O discurso, portanto, encerra a unidade de análise deste trabalho.

Todas as entrevistas foram gravadas com a anuência dos entrevistados e transcritas pelos próprios pesquisadores que adicionaram suas respectivas observações de campo. Segundo Yin (2016), tal procedimento contribui para minorar a necessidade de utilizar outros procedimentos para assegurar a validade da pesquisa. Ainda assim, para assegurar tal condição, as etapas de codificação, categorização e análise seguiram os princípios da reflexividade (GIBBS, 2009). Neste sentido, os textos das transcrições foram submetidos ao processo de codificação aberta e examinados pelos dois autores que possuíam à época, pelo menos, nove anos de experiência de ensino e que estavam familiarizados com as abordagens gerencial, de macromarketing e de marketing crítico. Esta rodada inicial ficou marcada por incongruências em relação à formação das categorias de análise, o que suscitou discussão a respeito de vieses inerentes às experiências profissionais e acadêmicas dos próprios pesquisadores. Sendo assim, uma rodada adicional fora empreendida dessa vez, havendo consenso sobre as categorias de análise produzidas a partir dos dados.

O processo de análise foi conduzido com base na análise crítica de discurso (WODAK; MEYER, 2015), que possibilita descrever as formações discursivas, a regulação de práticas discursivas por estruturas sociais e as possibilidades de agência dos indivíduos em relação a elas (WODAK; MEYER, 2015; SILVA; GONÇALVES, 2017). Van Dijk (2015) salienta que a análise crítica do discurso busca assimilar as relações existentes entre poder, discurso e dominação que ocorrem por meio do nexo entre a sociedade e a linguagem. Nota-se, no discurso dos professores, o predomínio da abordagem de marketing gerencial na prática de ensino. Ao mesmo tempo, as temáticas mais frequentemente desenvolvidas no âmbito de macromarketing e de marketing crítico são mencionadas, indicando que há espaços concedidos pelos próprios professores a essas duas escolas de pensamento no ensino da disciplina na graduação. 


\section{Análise e Discussão dos Resultados}

\section{A EXPERIÊNCIA ACADÊMICA E PRÁTICA DO PROFESSOR COMO RECURSO PARA SUPERAÇÃO DOS LIMITES APRESENTADOS PELOS CONTEÚDOS PROGRAMÁTICOS DA DISCIPLINA}

Conforme colocado anteriormente, os informantes desta pesquisa têm razoável experiência na docência de marketing, sendo que alguns, inclusive, exerceram, durante tempo considerável, o papel de praticantes em empresas de distintos tipos (institutos de pesquisa, agências de publicidade e propaganda, empresas produtoras de bens, varejo...). A experiência prévia no que se chama "mercado" é apontada como diferencial importante, como característica fundamental para a compreensão do que está contemplado na disciplina de marketing, por meio da sua prática profissional. Os entrevistados, embora mencionem frequentemente que os alunos não valorizam a atuação profissional como professores, acabam reforçando tal postura, ao considerar que ser praticante no mercado confere atuação superior do que um professor com formação acadêmica somente.

A ideia de que a teoria não é tão explicativa ou relevante quanto à prática, embora já tenha sido apontado em outros estudos (BACELLAR; IKEDA, 2007; IKEDA; BACELLAR, 2008), é fundamental aqui, porque nos permite observar uma característica atribuída aos programas das disciplinas de marketing hoje aplicados na graduação. Na visão dos respondentes, todos os programas são incompletos.

O reconhecimento unânime de que o programa das disciplinas de marketing não dá conta da complexidade da área, não é necessariamente visto como uma barreira intransponível. Muito pelo contrário, o trabalho do professor é visto a partir do que ele traz para o conteúdo programático por meio da sua vivência (profissional, eminentemente), sensibilidade e conhecimento. Nenhum dos entrevistados menciona as diretrizes de órgãos educacionais e a coordenação dos cursos ou instituições como orientadoras atentas do "quê" e de "como" será ensinado. Todos afirmam que, apesar de existirem regras, existe flexibilidade e liberdade na elaboração e até mesmo na execução do plano de ensino. Os limites apontados são o bom senso e a consciência crítica que o professor adquire no mestrado e no doutorado. 
Como a área de marketing, da maioria dos programas brasileiros de pós-graduação em administração é bastante influenciada pela literatura estrangeira e pela escola de pensamento gerencial na formação tanto de pesquisadores quanto de professores (VIEIRA, 2003; VELUDO-DE-OLIVEIRA; QUINTÃO; URDAN, 2014), fica mais latente o porquê de outras abordagens serem preteridas. Embora os entrevistados concordem que existe algum tipo de esforço das instituições em construir programas - ainda que tenham flexibilidade - a bibliografia mencionada por eles é, na esmagadora maioria, sinônimo de Phillip Kotler, tido como uma das principais referências do marketing gerencial. Embora os professores critiquem o uso quase que exclusivo de Kotler e mencionem tantos outros autores como importantes, no tocante à bibliografia das disciplinas de graduação, não parece haver muita diversidade: "Com relação aos autores você já citou o Kotler. Você poderia citar alguns outros autores que você utiliza? - Cara, eu vou ter que olhar a bibliografia porque eu não tenho isso de cabeça (risos)".

A maior parte dos entrevistados refere-se ao que seria o conteúdo básico do marketing, a partir da abordagem gerencial, caracterizando seu papel fundamental (“Aquele marketing beabá"), especialmente nas escolas onde não existem atividades de pesquisa: "O que se ensina lá, o básico né, o posicionamento, os 4 Ps, dentro dos 4 Ps estuda-se com mais detalhe cada um deles, a relação de um com o outro, mas sempre para o lucro, para o resultado".

A incompletude do programa é atribuída a diferentes causas: a falta de embasamento e experiência prática do professor e a inexperiência dos alunos com relação ao mundo dos negócios, bem como a própria natureza do curso de graduação (que exigiria algum nível de superficialidade). Para os informantes, tais pontos exigem que a disciplina seja um pouco mais superficial do que seria em um curso como o Mestrado. O curioso é que os entrevistados concordam que não necessariamente um curso no nível de Mestrado seria mais profundo somente em função das teorias e conceitos ensinados, mas também pelo ensino prático que só o mercado de trabalho seria capaz de oferecer. Este ponto é fundamental porque algumas técnicas pedagógicas entram como uma espécie de substitutas da prática profissional que o aluno ainda não possui. Frequentemente, os professores fazem referência a "trazer o mundo real para a disciplina" como forma de fomentar o pensamento crítico em alunos ainda imaturos com relação à vivência profissional. Tal 
entrada do mercado (o mundo real dos negócios) se daria pela inserção de casos de ensino, do uso de matérias de jornal e também pelas metodologias ativas que vem sendo objeto de treinamento por diversas instituições.

\section{AS PREOCUPAÇÕES SOBRE UM ENSINO DE MARKETING ORIENTADO PARA O MERCADO}

O mercado é apontado de maneira ambígua: ora como limitador (porque a empregabilidade dos egressos é considerada como nota de qualidade de um curso, então determinados conteúdos são "exigidos" pelo mercado de trabalho e isto limitaria a inclusão de visões alternativas), ora como lócus das atividades e de toda a teoria e conceitos de marketing. Neste último sentido, o mercado (e o marketing, por extensão) é visto como o lugar onde as empresas se relacionam com seus consumidores. $\mathrm{O}$ mercado é descrito como algo que deve ser observado atentamente pelos professores e do qual outras instituições e organizações, como, por exemplo, do âmbito público e do terceiro setor, não participam. Esta concepção de mercado está vinculada à abordagem micro vinculada ao marketing gerencial, que estabelece o discurso vencedor (KOTLER, 1979) sobre outras perspectivas, como as de macromarketing e de marketing crítico. Desta forma, os professores têm que: "[...] ter esse interesse em estar sempre olhando para fora, que eu chamo assim... que é do olhar do marketing (...) olhar para o mercado, para os consumidores, ver o que que tá mudando e o que que isso impacta”.

A definição do que é mercado é inteiramente compatível com a visão do marketing gerencial: mercados são agregados de consumidores, para os quais as empresas criam estratégias para influenciá-los e/ou atendê-los da melhor forma. Mesmo quando o conteúdo programático é descrito como limitado, ainda assim, a descrição é pouco clara quanto aos outros aspectos com que marketing se ocuparia. Frequentemente, variações da definição da orientação para marketing (que garantiriam o foco estratégico da empresa a longo prazo) são usadas para mostrar que a disciplina vai além das preocupações gerenciais. Este esforço talvez seja empreendido pelos professores como forma de realçar a relevância da disciplina (IKEDA; BACELLAR, 2008) frente à comparação que os alunos fazem com outras disciplinas do curso de Administração. 
Eu penso o marketing como uma área mais ampla, mas é... como aquilo vai dar pra gente uma visão mais de longo prazo. Não vejo o marketing só como fazer ação no ponto de venda; mas eu acho que no marketing, a preocupação que eu tenho, é que mostrar para esses caras que o marketing tem muito mais do que essa coisa dizer...dessa coisa de execução só relativo aos 4 Ps, né?

Não significa dizer que os sujeitos de pesquisa tenham uma postura "ingênua" sobre as empresas. Pelo contrário, apesar de desconsiderar fortemente organizações de outras naturezas, como as públicas e da sociedade civil, mencionando claramente somente as empresas como atores importantes, há a menção de problemas nas relações entre empresas e consumidores que mereceriam maior destaque em suas aulas. "Essa diferença entre o que a gente aprende no livro, que é o mundo perfeito consumidor acima de tudo, e as decisões que você tem que tomar dentro das empresas... com as decisões que você tem que operacionalizar dentro das empresas".

\footnotetext{
Você não muda essa lógica mudando uma disciplina na graduação, você muda essa lógica com outras providências, né? Se é que muda. Então, eu acho que a gente tem que usar dessa literatura sim, mas usar de maneira mais consciente, (...) mostrando para o aluno que essa literatura é assim, "ele vai trabalhar os 4 Ps pra no final das contas, ah, conquistar o cliente, reter o cliente, vender, dá lucro", mas ele também precisa ter consciência de que isso causa algum mal à sociedade, de que isso de certa maneira (...) impõe ao consumidor uma vulnerabilidade, é...praticamente cega o indivíduo. Você vê, a literatura de marketing trata todo mundo como consumidor. $O$ sujeito é, antes de qualquer coisa, consumidor. Esse é o problema. Não! Antes de qualquer coisa ele é um ser humano. Pelo menos deveria ser, entendeu?
}

Os trechos destacados expressam: 1) A percepção dos professores a respeito da inadequação do conteúdo dos livros e manuais de marketing com relação ao que é considerado o "mundo real”, o mercado; 2) A falácia da chamada soberania do consumidor, implicando no reconhecimento de que as empresas nem sempre tomam decisões que contribuem para o bem-estar de seus consumidores e da sociedade, como um todo; e 3) A primazia de dois dos agentes do mercado, o consumidor e a empresa; e 4) A impossibilidade de mudar tal situação, uma vez que há a percepção de que a prática profissional exigirá que o aluno aja conforme os padrões da empresa que o contrata. Tais padrões "de mercado" são frequentemente descritos como entidades superiores, inclusive no que diz respeito ao bem-estar societal. 
Conforme colocado anteriormente, os entrevistados priorizam como atores do mercado consumidores e empresas, existindo um grande silêncio a respeito de outros agentes. Somente quando estimulados a pensar para além dos agentes diretamente envolvidos em transações comerciais, é que a influência e a importância de entes como governo, agências reguladoras, formuladores de políticas públicas, entre outros, aparecem. "Eu não sei o que é mercado. Não é que eu não saiba. Assim, quando a gente fala mercado, as pessoas têm muitos entendimentos. Então, quando a gente fala mercado temos quer dizer qual o conceito que nós vamos usar".

Agora falando do ensino de marketing, a gente dá pouca importância a isso [definição de mercado]. A gente, eu quero dizer assim, os professores de marketing no Brasil dão pouca importância às políticas públicas influenciando o marketing; marketing norte-americano é a visão que eu tive; eu só tive acesso e só fui descortinar isso no mestrado.

O reconhecimento de que a literatura de marketing usada na graduação desconsidera - pelo menos em algum grau - outros agentes e suas relações, bem como as consequências das atividades mercadológicas, é a base principal das críticas feitas à disciplina. Como expõe um docente: "Quando a gente tá falando do marketing como um mercado, eu acho que as estratégias de mercado, boa parte delas são bem danosas".

\section{O LUGAR DA ÉTICA, DA CRÍTICA E DAS CONSEQUÊNCIAS NEGATIVAS NO ENSINO DE MARKETING}

Salientar problemas éticos nas relações entre empresas e clientes é, sem sombra de dúvida, a alteração mais importante e até mesmo útil para a vida profissional dos futuros administradores. Para a maior parte dos docentes entrevistados, uma solução para tal problema seria priorizar outras escolas de pensamento capazes de prover território mais firme para que essas discussões possam ser mais bem conduzidas pelos professores. No entanto, é bom lembrar que também existe o entendimento de que as técnicas de marketing que traduzem a implementação do conhecimento científico são amorais e que a dimensão da ética recai sobre os profissionais que as utilizam (IKEDA; BACELLAR, 2008). Essa tensão é preocupante por não permitir reflexão sobre a própria constituição da disciplina de marketing, o que demandaria uma postura crítica (SAREN, 2009) vinculada ao marketing crítico, muito embora a abordagem "social" reconheça a existência de consequências ne- 
gativas dos sistemas de marketing e lide com tais questões ao propor remediação para os problemas identificados.

Esse ponto seria de considerável importância para que o profissional recém-formado não pense somente na empresa: "[...]de um modo geral, eles ficam muito dentro do que a empresa pode fazer pra quase que enganar mais o consumidor". Embora os professores tenham uma visão que parece ser predominantemente positiva a respeito da disciplina, em vários momentos das entrevistas, o desconforto gerado por meio da observação dos problemas causados pelo marketing, em sua concepção hegemônica, fica visível no discurso: "Eu não vou conseguir ensinar marketing pro cara se eu ficar o tempo todo pensando nos impactos da sociedade". Tal desconforto implica em uma participação, uma responsabilização, mesmo que involuntária em problemas e não parece permitir uma solução final, mas ainda assim demonstra afinidade com a observação de Tadajewski (2011), que embora marketing seja visto como a disciplina com menos autocrítica, isto não seria inteiramente verdade.

\begin{abstract}
Entre o que nós ensinamos e o que é praticado existe uma diferença, existe um triângulo das bermudas. Depois que o cara começa a trabalhar, tem alguma coisa que acontece que transforma. E aí os caras, os caras são assim, nós, né? Nós profissionais de marketing, pessoas comuns, parece que a gente vive numa realidade paralela. Porque o cara vai para dentro da empresa e toma decisões onde ele quer a maximização do lucro (...) Então, pro céu eu sei que não vou, porque trabalhei em marketing. Esse cinismo, não sei se é cinismo, mas essa hipocrisia e tal, é praticada dentro das empresas, mas não é falada no ensino. Você não sai da faculdade achando isso. Você sai da faculdade achando que as empresas são boazinhas e que você realmente vai tomar as decisões para o bem do consumidor. Hoje eu acredito (...) minha principal missão é essa, é falar isso, desmistificar isso.
\end{abstract}

É interessante reparar como o professor se coloca como um militante, como um ativista, mas não muito radical, afinal são diversas as possibilidades de engajamento (SAREN, 2009) para inserir aos poucos, pontos relevantes na discussão. Os informantes sugerem ainda que tal postura vem dando resultado: "Ainda somos minoria, mas não somos mais os excluídos".

Eu propus um....lá no curso de marketing, uma ementa, um plano de ensino mais crítica, né? Que vai falar de sistema de mercado, sistema de marketing, como funciona. Vai 
falar de consequências sociais desse sistema de marketing, vai falar de política pública, marketing informando política pública [...] os que estão fora da sala de aula e estão fora da indústria, acho que este pode criticar [...] Tem que aumentar o coro, entendeu?

"E agora existe uma preocupação da sociedade em cobrar das empresas, que as decisões não sejam só pautadas pelo lucro. Os alunos fazem parte dos dois lados, né? Eles são sociedade e eles são empresas, né?"

A mencionada imaturidade do aluno, a condição de tábula rasa (IKEDA; BACELLAR, 2008) (que seria superada somente com a vivência profissional no mercado), também seria visível na dificuldade dos discentes em observar tais problemas de mercado como oriundos até mesmo da prática das empresas. Mais uma vez, a solução apontada seria a sensibilidade do professor para colocar tais temas em discussão com todas as adversidades que podem emergir

[...] assim, uma rejeição de início que leva um tempo, né? Então, como eu não sou uma pessoa radical, eles acabam vendo que, que dá pra ouvir e ter outros espaços. Mas não é um trabalho fácil, nem que você consiga, "Ah, esse papo tá muito zen" (risos). Como se fosse algo que não existe no mundo....

De uma maneira geral, os entrevistados reconhecem em distintos graus as consequências negativas das atividades de marketing na sociedade e relacionam tais consequências aos conteúdos ensinados em marketing, mas creem ter um poder de agência bastante reduzido para transformar a situação. A abordagem gerencial é descrita como básica, fundamental para a formação exigida pelo mercado, mas, ao mesmo tempo, é considerada insuficiente e superficial, exigindo que o professor traga conteúdo mais "crítico". Crítica, aqui é frequentemente usada como a capacidade de compreensão e interpretação de dados e informações complexas, com a aplicação dos conceitos básicos de marketing gerencial, portanto, não está diretamente vinculada ao marketing crítico. A alta performatividade da abordagem gerencial no discurso dos professores é compatível com já mencionada popularização dos conceitos pertinentes à gestão de marketing centrada na empresa, na compreensão do mercado enquanto conjunto de consumidores e na marginalização de determinados conteúdos, como vários apontam (e.g. WILKIE; MOORE, 2003; SHAW; JONES, 2005; ELLIS et al., 2011; FARIA, 2015). 
Embora marginalizadas, algumas temáticas relacionadas a problemas que podem ser causados pela atividade de marketing são reconhecidas como pertinentes e relevantes. Os professores mencionam inicialmente receber das escolas e das coordenações muita liberdade para inclusão de assuntos no programa e na sala de aula, mas em todos os depoimentos fica claro qual estrutura restringe a ampliação da discussão de determinados assuntos: o mercado. Embora haja o reconhecimento da dimensão política do mercado em marketing, dos problemas causados pela prática das empresas e o quão importantes outros agentes podem ser dentro do sistema de marketing (agentes reguladores, governos, entre outros tantos), tais discussões devem ser conduzidas à luz do benefícios (financeiro, eminentemente) que podem trazer às empresas (ente prioritário dentro do sistema).

Esse ponto indica que há, por parte dos professores, o reconhecimento de outras abordagens de marketing que seriam fundamentais para a compreensão da realidade dos mercados e sua influência sobre a sociedade. Mesmo que não tenham sido identificadas por todos os entrevistados, especificamente, como temáticas e preocupações existentes nos domínios do macromarketing e do marketing crítico, tais objetos pertencem a este domínio, sendo mais claro no primeiro, quando observadas as consequências das relações estabelecidas pelos sistemas de marketing sobre a sociedade em termos de danos ambientais e quando afetam a saúde da população. Já as questões éticas e a forma com que orientam decisões organizacionais aludem a temáticas discutidas no marketing crítico. Frequentemente, o termo "Marketing Social" é tido como importante para descrever algumas das problemáticas necessárias. Menos do que mero desconhecimento do que seria a abordagem de macromarketing ou de marketing crítico, a ênfase no social parece indicar que os professores se veem em um estreito espaço de agência entre o que é fundamental para a formação do aluno (o que o mercado "deseja" e "valoriza") e o que é possível incluir em tal espaço. Este ponto é fundamental porque revela uma dimensão de autorresponsabilização e até mesmo de insegurança.

Existe um parco reconhecimento do que seria marketing crítico e, de até mesmo, de sua viabilidade em uma escola de negócios, consistente com os achados de Paula e Rodrigues (2006). As dificuldades seriam oriundas da formação deficitária dos professores e da falta de interesse da instituição. O mencionado estreito espaço de agência dos professores tem como limites claros as avaliações 
(do professor, do curso e a taxa de aprovação da disciplina), e, em última instância, a empregabilidade dos alunos e, portanto, a aceitação do mercado. A dimensão da avaliação é consistente com um mercado que vem precarizando as relações de trabalho de professores e com o aumento de demissões recentes em várias instituições de ensino. O discurso revela também o poder disciplina da abordagem gerencial, acrescida de uma desconfiança da utilidade de conteúdos mais críticos, uma vez que a dimensão ideológica do marketing seria inevitável.

Eu sei que isso é importante, tudo bem... Mas, é uma coisa paralela. (...) É dentro de um contexto ético. Mas, esses impactos... não, eu preciso vender, preciso ganhar share de mercado, preciso ter ticket médio, eu quero que meu concorrente fique achatado, entendeu? Eu acho que isso tem muito a ver com meu passado profissional. Eu não vou ficar pensando (...). Eu não vou conseguir ensinar marketing pro cara se eu ficar o tempo todo pensando nos impactos da sociedade. Entendeu?

Por fim, os dados coletados junto aos professores permitiram a elaboração do quadro 3 que resgata as três ênfases que os currículos das disciplinas possuem sobre a prática de marketing, a perspectiva a ser adotada e o que deve ser ensinado. Segundo os informantes, a ênfase "tradicional", baseada na escola de pensamento gerencial, enquadra a prática de marketing em função da sua contribuição para aprimorar o desempenho de uma organização empresarial. A perspectiva adotada se restringe às relações econômicas entre empresas e consumidores, o que direciona o foco para o ensino de teorias e conceitos que produzam valor para esses dois atores. Já a ênfase "social", próxima à escola de pensamento de macromarketing, enquadra a prática de marketing para aprimorar o desempenho tanto de organizações empresariais quanto governamentais, incluindo as relações políticas às econômicas que cercam o relacionamento entre empresas, consumidores e governos. Foco recai sobre os efeitos positivos e negativos que a prática de marketing pode produzir quando colocada em perspectiva o relacionamento entre esses três atores. Por último, a ênfase "crítica", próxima à escola de pensamento de marketing crítico, enquadra a prática de marketing nos domínios das organizações governamentais e da sociedade civil organizada, ressaltando sobretudo suas dimensões éticas. O ensino priorizaria as dimensões políticas e de poder entre empresas, consumidores e sociedade. 
Quadro 3 Comparação entre as ênfases em currículos tradicionais, sociais e críticos em disciplinas de marketing a partir dos dados coletados junto aos professores.

\begin{tabular}{|c|c|c|c|}
\hline & Ênfase "Tradicional" & Ênfase "Social" & Ênfase "Crítica" \\
\hline 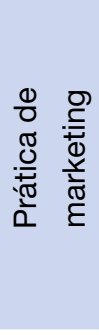 & $\begin{array}{l}\text { Orientada para forma- } \\
\text { ção de praticantes ca- } \\
\text { pazes de contribuir para } \\
\text { o desempenho de orga- } \\
\text { nizações empresariais. }\end{array}$ & $\begin{array}{l}\text { Orientada para a formação } \\
\text { de praticantes capazes de } \\
\text { contribuir para o desempe- } \\
\text { nho de organizações empre- } \\
\text { sariais e governamentais. }\end{array}$ & $\begin{array}{l}\text { Orientada para a for- } \\
\text { mação de praticantes } \\
\text { capazes de contribuir } \\
\text { para o desempenho de } \\
\text { organizações governa- } \\
\text { mentais e da sociedade } \\
\text { civil organizada. }\end{array}$ \\
\hline 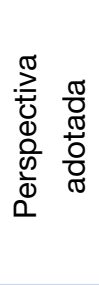 & $\begin{array}{l}\text { Marketing estudado } \\
\text { a partir de uma pers- } \\
\text { pectiva centrada nas } \\
\text { relações econômicas } \\
\text { entre empresas e con- } \\
\text { sumidores. }\end{array}$ & $\begin{array}{l}\text { Marketing estudado a partir } \\
\text { de uma perspectiva centrada } \\
\text { nas relações econômicas } \\
\text { e políticas entre empresas, } \\
\text { consumidores e governos. }\end{array}$ & $\begin{array}{l}\text { Marketing estudado a } \\
\text { partir de uma perspecti- } \\
\text { va centrada nas dimen- } \\
\text { sões éticas e pressões } \\
\text { oriundas da sociedade } \\
\text { civil organizada. }\end{array}$ \\
\hline 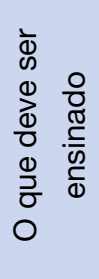 & $\begin{array}{l}\text { Prioriza o ensino de } \\
\text { teorias e conceitos } \\
\text { sobre a melhor adequa- } \\
\text { ção das operações da } \\
\text { empresa ao mercado } \\
\text { consumidor. }\end{array}$ & $\begin{array}{l}\text { Prioriza o ensino de teorias e } \\
\text { conceitos que consideram os } \\
\text { efeitos positivos e negativos } \\
\text { sobre a sociedade oriundos } \\
\text { do relacionamento entre em- } \\
\text { presas e consumidores. }\end{array}$ & $\begin{array}{l}\text { Prioriza o ensino de } \\
\text { teorias e conceitos que } \\
\text { desvelem as dimensões } \\
\text { políticas e de poder } \\
\text { entre empresas, consu- } \\
\text { midores e sociedade. }\end{array}$ \\
\hline
\end{tabular}

Fonte: Elaborado pelos autores, a partir dos achados da presente pesquisa e de Guagliardi (1983), Catterall, Maclaran e Stevens (2002), Wilkie e Moore (2003; 2006) e Berardinelli e Sauerbronn (2017).

É importante ressaltar que o Quadro 1 tem a função de mostrar as diferentes características de cada ênfase, mas nossos dados sugerem que na prática docente cotidiana existem nuances localizadas entre cada delas.

\section{Considerações Finais}

O objetivo deste trabalho era investigar quão plural é o ensino de marketing ao nível da graduação dos cursos de Administração, considerando três escolas de pensamento: a gerencial, a de macromarketing e a de marketing crítico. Para 
tanto, foi adotado um desenho de pesquisa qualitativa para acessar no discurso de professores que lecionam disciplinas relacionadas à marketing, em cursos de Administração do Rio de Janeiro, quais são as principais abordagens que orientam os currículos, as ementas e a práticas de ensino que mediam a aprendizagem em sala de aula. Os resultados apresentados nas três categorias analíticas produzidas apontam para: a) O reconhecimento de que o conteúdo programático não atende aos desafios que cercam a prática de marketing; b) A preocupação em referenciar as práticas de marketing às demandas do mercado e; c) A importância de estabelecer discussões éticas, sociais e críticas que envolvam não somente a relação entre empresas e consumidores, mas que incluam o papel do Estado e as pressões da sociedade civil organizada.

O conteúdo programático se mostra insuficiente à medida que há o predomínio de livros que segue a abordagem gerencial de marketing. Tal literatura é recoberta de legitimidade, uma vez que dispõe de semelhante status nos cursos de pós-graduação stricto sensu em Administração (VIEIRA, 2003; VELUDO-DE-OLIVEIRA; QUINTÃO; URDAN, 2014). Vale salientar ainda que boa parte desta literatura é composta por autores estrangeiros que, por vezes, apresentam exemplos que não necessariamente encontram paralelo com a realidade brasileira. Nos casos das obras nacionais, mesmo que apresentem problemas de organizações facilmente reconhecidas pelos alunos, reproduzem conceitos e técnicas que visam aprimorar o relacionamento entre empresas e consumidores em termos econômicos.

Foi possível perceber tanto pela revisão de literatura quanto pelos dados produzidos pelos professores entrevistados, que a hegemonia desta escola de pensamento exerce forte influência não só sobre o que deve ser ensinado, mas também sobre a formação dos pesquisadores e futuros professores de marketing. Se desejado um ensino de marketing mais plural na graduação, os programas de pós-graduação também desempenham um importante papel a cumprir. Um professor entrevistado alegou que somente conheceu outras abordagens de marketing, pelo contato que teve ao longo de sua trajetória nos cursos de mestrado e de doutorado em uma instituição de ensino que zelava justamente por um programa mais heterogêneo. Desta forma, os programas de pós-graduação contribuiriam com a formação mais plural dos professores se também adotassem 
livros e periódicos que abordassem temáticas relacionadas ao macromarketing e ao marketing crítico, incluindo no rol de periódicos contemplados, além daqueles mais conhecidos, tais como Journal of Marketing, artigos provenientes do Journal of Macromarketing, do Marketing Theory e, o que pode até surpreender, do Journal of Marketing Management, que abriga discussões críticas. No Brasil, embora as publicações baseadas nestas duas escolas de pensamento sejam ainda escassas, vale mencionar o livro Marketing e Sociedade (COSTA, 2015) que versa sobre macromarketing.

Embora os professores atribuam importância do ensino de técnicas e conceitos da abordagem gerencial para ampliar as chances de ingresso dos alunos no mercado de trabalho, baseado em empresas (sem especificar porte ou natureza - se pública ou privada), o que sugere contornos ideológicos, também nutrem um sentimento de ceticismo quando se detém para avaliar o relacionamento assimétrico de poder entre esses atores junto aos consumidores. Nestes momentos, há menções sobre formulação de políticas públicas sobre regulação governamental e pressões da sociedade civil, que exercem impactos sobre as práticas de marketing e, que, por este motivo, deveriam ter espaço para discussões em sala de aula. Neste sentido, mesmo que não haja enquadramento claro por parte dos professores dos temas afeitos às abordagens de macromarketing e de marketing crítico, elas já são trabalhadas de alguma forma pelos docentes por meio de utilização, por exemplo, de casos de ensino que abordem questões de gênero, o consumismo e as condições de vulnerabilidade do consumidor, o que nos indica que há sobreposição das ênfases apresentadas no Quadro 1 como alternativas à Gerencial.

Tais temáticas parecem caminhar por uma zona cinzenta que apresenta desafios e penalidades aos professores. Em parte, isso pode ocorrer porque desafiam as expectativas dos alunos que podem inflar a glamourização de determinados assuntos, como marca e publicidade, escapar de conteúdos cobrados pelo Exame Nacional de Desempenho de Estudantes, o ENADE, cuja nota repercute sobre a avaliação do curso e tem efeitos negativos sobre a própria avaliação do professor. Com este cenário, a abertura ao diálogo com coordenadores dos cursos, o apoio da instituição de ensino e formalização de intenções mais plurais sobre o ensino de marketing nos projetos pedagógicos, são cruciais. Em contrapartida, práticas 
de ensino podem não estar restritas aos domínios da sala de aula e podem avançar sobre atividades de ensino e de extensão que também são importantes para avaliação dos cursos. Dado que a abordagem de macromarketing resgata o papel do Estado e a forma com que participa do relacionamento entre empresas e consumidores, tendo por objetivo o incremento da qualidade de vida da população e que a abordagem de marketing crítico lança luz sobre as pressões sociais que denunciam aspectos nocivos das práticas de marketing, abrem-se uma série de possibilidades para elaboração de projetos de pesquisa e de extensão que incluam a participação dos alunos.

Em termos teóricos, o discurso dos professores desafia as fronteiras ontológicas e epistemológicas estabelecidas na academia. Também como praticantes de marketing, transitam, por exemplo, entre as abordagens gerencial e crítica tidas como antagônicas e incomensuráveis. O terreno que tende a prover maior segurança parece ser o de macromarketing. Não à toa que é possível identificar com certa facilidade temáticas gerenciais e críticas nos seus domínios. Isso pode ser explicado pelo seu escopo amplo e orientação de pesquisa que busca investigar os impactos das práticas de marketing na sociedade e vice-versa.

A potencialidade de adoção de discussões presentes nas Escolas do Macromarketing e do Marketing Crítico nos permite vislumbrar potencial de pesquisas futuras que utilizem perspectivas que tornem mais claras as consequências para a disciplina e prática de marketing, privilegiar como lócus único de produção de conhecimento o Norte Global (ABDALLA; FARIA, 2017; FARIA; HEMAIS, 2017; HEMAIS, 2019), desconsiderando saberes e tradições locais (DALMORO, PEÑALOZA, NIQUE, 2016).

Por fim, seria relevante o desenvolvimento de pesquisas futuras que investiguem, junto a alunos, egressos e coordenadores dos cursos de Administração, o entendimento e a relevância atribuída ao ensino de marketing e suas diferentes ênfases curriculares. Os resultados poderiam possibilitar o reforço e/ou a descoberta de novos rumos para discussão, e, quem sabe, para a disciplina de marketing mais plural. 


\section{Referências}

ABDALLA, M. M., FARIA, A. Em defesa da opção decolonial em administração/gestão. Cadernos EBAPE. BR, v.15, n. 4, p. 914-929, Out./Dec. 2017. DOI: 10.1590/1679-395155249.

AJZENTAL, A. Uma história do pensamento em marketing. 2008. 272 f. Tese (Doutorado em Administração de Empresas) - Escola de Administração de Empresas de São Paulo, Fundação Getúlio Vargas, São Paulo, 2008.

ALVESSON, M.; WILLMOTT, H. (Eds.). Making sense of management: a critical analysis. London: Sage, 1993.

ANDERSON, D. The consumer and the agricultural adjustment administration. Journal of Marketing, v. 1, n. 1, p. 3-12, July 1936. DOI: 10.1177/002224293600100101.

ARNDT, J. How broad should the marketing concept be? Should it be developed into a full-fledged behavioral science? Journal of Marketing, v. 42, n. 1, p. 101-103, Jan. 1978. DOI: 10.1177/002224297804200118.

. On making marketing science more scientific: the role of orientations, paradigms, metaphors, and puzzle solving. Journal of Marketing, v. 49, n. 3, p. 11-23, June 1985. DOI: 10.1177/002224298504900302. BACELLAR, F. C. T.; IKEDA, A. A. Evolução do ensino de marketing: um breve histórico. Organizações \& Sociedade, v. 18, n. 58, p. 487-511, jul./set. 2011. DOI: 10.1590/S1984-92302011000300008.

Ensinar marketing na visão dos seus professores. Organizações \& Sociedade, v. 14, n. 42, p. 151-165, jul./set. 2007. DOI: 10.1590/S1984-92302007000300009.

BAKER, M.; SAREN, M. Marketing theory: a student text. 2rd ed 2. London: Sage, 2010. 448 p.

BALMER, J. M. T.; BURGHAUSEN, M. Marketing, the past and corporate heritage. Marketing Theory, v. 19, n. 2, p. 217-227, Aug. 2019. DOI: 10.1177/1470593118790636.

BARBOZA, S. I. S.; SILVA, W. F. D. Contribuições do marketing social na formação do administrador. Administração: Ensino e Pesquisa, (RAEP), v. 20, n. 2, p. 286-318, mai./ago. 2019. DOI: 10.13058/ raep.2019.v20n2.1328.

BERARDINELLI, R. P.; SAUERBRONN, J. F. R. Contribuições do macromarketing para a formação de administradores: podemos melhorar o ensino de marketing em cursos de graduação em administração? Administração: Ensino e Pesquisa (RAEP), v. 18, p. 558-593, set./dez. 2017. DOI: 10.13058/raep.2017. v18n3.628.

BEVILACQUA, S.; MEDEIROS, C. R. O. A pesquisa científica que critica a publicidade estereotipada: uma busca histórica nas publicações em marketing e publicidade (1971-2018). Revista de Ciências da Administração, v. 21, n. 53, p. 160-176, abr. 2019. DOI: 10.5007/2175-8077.2019V21n53p160.

BOAVENTURA, P. S. M. et al. Desafios na formação de profissionais em Administração no Brasil. Administração: Ensino e Pesquisa (RAEP), v. 19, n. 1, p. 1-31, jan./abr. 2018. DOI: 10.13058/raep.2018.v19n1.775. BOSCHI, M. R.; BARROS, D. F.; SAUERBRONN, J. F. R. A introdução da disciplina de marketing no Brasil: "uma linguagem comum que nos une". Farol - Revista de Estudos Organizacionais e Sociedade, v. 3, n. 8, p. 857-924, dez. 2017. DOI: 10.25113/farol.v3i8.3872.

CATTERALL, M.; MACLARAN, P.; STEVENS, L. Critical Reflection in the Marketing curriculum. Journal of Marketing Education, v. 24, n. 3, p. 184-192, Dec. 2002. DOI: 10.1177/0273475302238041. 
CONEJO, F. J.; WOOLISCROFT, B. Historical marketing systems research: applying Layton's (2015) MAS framework to the emergence and growth of Denver begging systems. In: MACROMARKETING CONFERENCE, 43, 2018, Leipzig. Anais... Leipzig: MMC, 2018, p. 884-920. Disponível em: <http://society.macromarketing.org/assets/proceedings/2018-macromarketing-proceedings.pdf >. Acesso em: 07 set. 2019. COSTA, F. Marketing \& Sociedade. João Pessoa: Editora da UFPB, 2015. 254 p.

DALMORO, M.; PEÑALOZA, L.; NIQUE, W. M. Market resistance in developing nations: the sustenance of Gaucho consumer culture in Brazil. In: Groza M., Ragland C. (eds.) Marketing Challenges in a Turbulent Business Environment. Developments in Marketing Science: Proceedings of the Academy of Marketing Science. Springer, Cham, 2016. p. 267-268.

DAVEL, E.; ALCADIPANI, R. Estudos críticos em administração: a produção científica brasileira nos anos 1990. Revista de Administração de Empresas, v. 43, n. 4, p. 72-85, out./dez. 2003. DOI: 10.1590/S003475902003000400006.

DINIZ, A. et al. Marketing crítico: precisamos falar sobre isso. In: ENCONTRO DE MARKETING DA ASSOCIAÇÃO NACIONAL DE PÓS-GRADUAÇÃO E PESQUISA EM ADMINISTRAÇÃO, 7, 2016, Belo Horizonte. Anais...Belo Horizonte: ANPAD, 2016, p. 1-18. Disponível em: https://www.researchgate. net/profile/Elder_Semprebon/publication/304806650_Marketing_Critico_Precisamos_falar_sobre_isso/ links/577bba1808ae213761caaf81/Marketing-Critico-Precisamos-falar-sobre-isso.pdf. Acesso em: 15 set. 2019.

DOMEGAN, C. et al. A Dynamic stakeholders framework in a marketing systems setting. Journal of Macromarketing, v. 39, n. 2, p. 136-150, Apr. 2019. DOI: 10.1177/0276146719835287.

DUFFY, S.; LAYTON, R. The struggle to govern the commons and how marketing can help. In: MACROMARKETING CONFERENCE, 40, 2015, Chicago. Anais... Chicago: MMC, 2015, p. 73-84. Disponível em: <http://society.macromarketing.org/assets/proceedings/2015-macromarketing-proceedings.pdf>. Acesso em: 07 set. 2019.

EASTERBY-SMITH, M.; THORPE, R.; JACKSON, P. Management \& Business Research. London: SAGE, 2015. $400 \mathrm{p}$.

ELLIS, N. et al. Marketing: a critical textbook. London: SAGE, 2011. 256 p.

ENGLERT, N. F. et al. Redução do escopo ou ampliação da prática? As perspectivas do marketing na visão de seus acadêmicos. REAd. Revista Eletrônica de Administração, v. 24, n. 2, p. 167-188. Maio/ago. 2018. DOI: $10.1590 / 1413-2311.206 .82108$.

ERTEKIN, Z. O.; ATIK, D. Aging of youth through fashion: influential dynamics and societal implications. In: MACROMARKETING CONFERENCE, 40, 2015, Chicago. Anais... Chicago: MMC, 2015, p. 38-53. Disponível em: <http://society.macromarketing.org/assets/proceedings/2015-macromarketing-proceedings.pdf>. Acesso em: 07 set. 2019.

FALCÃO, R. F. O marketing no Brasil: sua história e evolução. 2014. 374 f. Dissertação (Mestrado em Administração) - Faculdade de Economia, Administração e Contabilidade, Universidade de São Paulo, São Paulo, 2014.

FARIA, A. Rethinking market-ing orientation: a critical perspective from an emerging economy. In: PRASAD, A. et al. (Ed.). The Routledge Companion to Critical Management Studies. New York: Routledge, 2015. p. 217-235. 
Quão Plural é o Ensino de Marketing? Um Estudo Exploratório com Professores dos Cursos de Graduação em Administração How Plural is the Teaching of Marketing? An Exploratory Study with Teachers of Undergraduate Business Course

Daniel de Oliveira Barata Merabet | Rosana Oliveira da Silva | Clayton Pereira Gonçalves | Denise Franca Barros

.; GUEDES, A. Movimento cultural nos estudos organizacionais: uma abordagem interdisciplinar focada no consumo e na globalização. Cadernos EBAPE.BR, v. 3, n. 1, p. 1-16, mar. 2005. DOI: 10.1590/ S1679-39512005000100003.

.; HEMAIS, M. Rethinking the bottom of the pyramid: A critical perspective from an emerging economy. Marketing Theory, v. 17, n. 3, p. 271-287, May 2017. DOI: 10.1177/1470593117704283.

FERREIRA, M. D. S.; BARROS, D. F. Falhas de mercado e respostas regulatórias: o macromarketing como perspectiva de análise do mercado de suplementos alimentares. In: CONGRESSO NACIONAL DE ADMINISTRAÇÃO E CONTABILIDADE, 9, 2018, Rio de Janeiro. Anais... Rio de Janeiro: AdCont, 2018, p. 1-15. Disponível em: http://adcont.net/index.php/adcont/adcont2018/paper/view/3125/955. Acesso em: 25 set. 2019.

FERRELL, O. C. et al. Understanding the history of marketing education to improve classroom instruction. Marketing Education Review, v. 25, n. 2, p. 159-175, June 2015. DOI: 10.1080/10528008.2015.1038963. FLEMING, M. C. N. C. et al. Explorando a matriz social de um sistema de marketing: o caso Serra Pelada. Revista Alcance, v. 22, n. 4, p. 586-601, out./dez. 2015. DOI: alcance.v22n4.p586-601.

GIBBS, G. Análise dos dados qualitativos. Tradução de Roberto Cataldo Costa. Coleção Pesquisa Qualitativa. Porto Alegre: Artmed, 2009. 198 p.

GUAGLIARDI, J. A. A relação ensino/prática de marketing na cidade de São Paulo: realidade e perspectiva. Revista de Administração da Universidade de São Paulo, v. 18, n. 2, p. 96-99, abr./jun. 1983.

HACKLEY, C. Parallel universes and disciplinary space: the bifurcation of managerialism and social science in marketing studies. Journal of Marketing Management, v. 25, n. 7-8, p. 643-659, Feb. 2009. DOI: 10.1362/026725709X471541.

HAGERTY, DR. J. E. Experiences of an early marketing teacher. Journal of Marketing, v. 1, n. 1, p. 20-27, June 1936. DOI: 10.1177/002224293600100104.

HEMAIS, M. W. Eurocentric influence on the 23ngland23m consumer defense code. Journal of Historical Research in Marketing, v. 11, n. 2, p. 203-226, May 2019. DOI: 10.1108/JHRM-12-2017-0073.

HUNT, S. The nature and scope of marketing. Journal of Marketing, v. 40, n. 3, p. 17-28, July 1976. DOI: 10.1177/002224297604000304.

IKEDA, A.; BACELLAR, F. Revelando e compreendendo o relacionamento professor-aluno em marketing. Revista de Administração Mackenzie, v. 9, n. 5, p. 137-154, jul./ago. 2008. DOI: 10.1590/S167869712008000500007.

ITUASSU, C. T.; ABREU, M. S.; FICHE, R. H.; MARANHÃO, C. M. S. D. A. Marketing e estudos organizacionais: o fim do divórcio. Revista Interdisciplinar de Gestão Social, v. 4, n. 1, p. 139-161, jan./mar. 2015.

JONES, D. G. B.; MONIESON, D. D. Early development of the philosophy of marketing thought. Journal of Marketing, Chicago, v. 54, n. 1, p. 102-113, Jan. 1990. DOI: 10.1177/002224299005400107.

.; SHAW, E. H. Avoiding academic irrelevance in the marketing discipline: the promise of the history of marketing thought. Journal of Marketing Management, v. 34, n. 1/2, p. 52-62, Nov. 2018. DOI: 10.1080/0267257X.2017.1398771.

JUSTEN, A.; GURGEL, C. Cursos de Administração: a dimensão pública como sujeito excluído. Cadernos EBAPE. BR, v. 13, n. 4, p. 852-871, out./dez. 2015. DOI: 10.1590/1679-395112349. 
Quão Plural é o Ensino de Marketing? Um Estudo Exploratório com Professores dos Cursos de Graduação em Administração How Plural is the Teaching of Marketing? An Exploratory Study with Teachers of Undergraduate Business Course

Daniel de Oliveira Barata Merabet | Rosana Oliveira da Silva | Clayton Pereira Gonçalves | Denise Franca Barros

KLEIN, T. A. Comments on "marketing systems and market failure". Journal of Macromarketing, v. 39, n. 1, p. 106-107, Dec. 2019. DOI: 10.1177/0276146718820939.

KOTLER, P. Strategies for introducing marketing into nonprofit organizations. Journal of Marketing, v. 43, n. 1, p. 37-44, Jan. 1979. DOI: 10.1177/002224297904300104.

LAW, P.; WENSLEY, R. Marketing teaching. European Journal of Marketing, v. 13, n. 1, p. 15-26, Jan. 1979. DOI: 10.1108/EUM0000000004928.

LAYTON, R. Marketing systems - looking backward, sizing up and thinking ahead. Journal of Macromarketing, v. 39, n. 2, p. 208-224, Jan. 2019. DOI: 10.1177/0276146718823897.

.; GROSSBART, S. Macromarketing: past, present and possible future. Journal of Macromarketing, v. 26, n. 2, p. 193-213, Dec. 2006. DOI: 10.1177/0276146706294026.

MARANHÃO, C. M. S. D. A.; MOTTA, F.; LEITÃO, P. Por uma educação critica em marketing: o modelo das três dicotomias de Hunt como ferramenta introdutória? In: ENCONTRO DA ASSOCIAÇÃO NACIONAL DE PÓS-GRADUAÇÃO E PESQUISA EM ADMINISTRAÇÃO, 30, 2006, Salvador. Anais... Salvador: ANPAD, 2006, p. 1-16. Disponível em: <http://www.anpad.org.br/admin/pdf/enanpad2006-epqa-1181. pdf $>$. Acesso em: 20 set. 2019.

.; PAES DE PAULA, A. P. Estudos críticos sobre marketing: levantamento da produção científica. Revista de Administração FACES Journal, v. 11, n. 1, p. 34-46, jan./mar. 2012. DOI: 10.21714/1984-6975FACES2012V11N1ART1129.

NASON, R. The social consequences of marketing: macromarketing and public policy. Journal of Public Policy and Marketing, v. 8, p. 242-251, Jan. 1989. DOI: 10.1177/074391568900800116.

OLIVEIRA, A. L.; LOURENÇO, C. D. S.; CASTRO, C. C. Ensino de administração nos EUA e no Brasil: uma análise histórica. Pretexto, v. 16, n. 1, p. 11-22, jan./mar.2015. DOI: 10. 21714/pretexto.v16i1.1830. PAES DE PAULA, A.; RODRIGUES, M. Pedagogia crítica no ensino da administração: desafio e possibilidades. Revista de Administração de Empresas, v. 46, edição especial Minas Gerais, nov./dez. 2006. DOI: 10.1590/S0034-75902006000500001.

PATSIAOURAS, G. Marketing concepts can have a life of their own: representation and pluralism in marketing concept analysis. Marketing Theory, p. 1-8, July 2019. DOI: 10.1177/1470593119865932.

PEREIRA, K. Consequências da ação organizacional sob a perspectiva de macromarketing: o mercado da morte. 2016. 123 f. Dissertação (mestrado em administração) - Escola de Ciências Sociais Aplicadas da Universidade do Grande Rio, RJ, 2016.

RADFORD, S. K.; HUNT, D. M.; ANDRUS, D. Experiential learning projects. Journal of Macromarketing, v. 35, n. 4, p. 466-472, Mar. 2015. DOI: 10.1177/0276146715573834.

REDMOND, W. Marketing systems and market failure: a macromarketing appraisal. Journal of Macromarketing, v. 38, n. 4, p. 415-424, Aug. 2018. DOI: 10.1177/0276146718796913.

RICHARDSON, R. J. Pós-graduação-metodologia-pesquisa social: métodos e técnicas-métodos quantitativos e qualitativos. São Paulo: Atlas, 2017. 424 p.

ROGERS, R. Critical discourse analysis in education. In: WORTHAM S., KIM, D., MAY, S. (eds) Discourse and education (3 ed.). [S.I.]: Springer, 2017. p. 41-54.

SALVÁ, M. N. R.; BAUER, A. P. M.; WANDERLEY, S. E. D. P. V. O mercado da educação superior no Brasil: uma internacionalização Reversa? In: COLÓQUIO INTERNACIONAL DE GESTÃO UNIVERSITÁRIA, 19, 2019, Florianópolis. Anais... Florianópolis: CIGU, p. 1-13, 2019. 
SALVADOR, A. B.; IKEDA, A. A. O uso de metodologias ativas de aprendizagem em MBA de marketing. Cadernos EBAPE. BR, v. 17, n. 1, p. 129-143, jan./mar. 2019. DOI: 10.1590/1679-395168522.

SAREN, M. Modes of engagement for critical marketing: oppositional, revivalist and therapeutic. Journal of Marketing Management, v. 25, n. 7-8, p. 843-848, Feb. 2009. DOI: 10.1362/026725709X471686.

SCHROEDER, J. E. Critical marketing: insights for informed research and teaching. In: SAREN, M. et a. Critical Marketing: Defining the Field. Oxford: Butterworth-Heinemann, 2007. p. 18-29.

SCUSSEL, F. B. C. Poder, paradigmas e domínio na pesquisa em marketing no Brasil: uma análise da produção nacional da disciplina a partir das matrizes epistêmicas. Administração: Ensino e Pesquisa (RAEP), v. 18, n. 3, p. 518-557, set./dez. 2017. DOI: 10.13058/raep.2017.v18n3.702.

SHAPIRO, S. J. In search of macromarketing history: eighteenth century England as a case in point. In: MACROMARKETING CONFERENCE, 40, 2015, Chicago. Anais... Chicago: MMC, 2015, p. 237-238. Disponível em: <http://society.macromarketing.org/assets/proceedings/2015-macromarketing-proceedings.pdf>. Acesso em: 07 set. 2019.

SHAW, E. H. Teaching the history of marketing thought: an approach. Journal of Historical Research in Marketing, v. 7, n. 2, May 2015.

.; JONES, D. G. A history of schools of marketing thought. Marketing Theory, v. 5, n. 3, p. 239-281, Sep. 2005. DOI: 10.1177/1470593105054898.

SILVA, E. R. D.; GONÇALVES, C. A. Possibilidades de incorporação da análise crítica do discurso de Norman Fairclough no estudo das organizações. Cadernos EBAPE. BR, v. 15, n. 1, p. 1-20, jan./mar. 2017. DOI: 10.1590/1679-395132088.

SILVA, R. O. D. O mercado do morrer: análise das práticas de mercado como criadoras da vulnerabilidade do consumidor. 2018. 192 f. Dissertação (mestrado em administração) - Escola de Ciências Sociais Aplicadas da Universidade do Grande Rio, Rio de Janeiro, 2018.

.; BARROS, D. F.; GOUVEIA, T. M. D. O. A. Eu tenho a força! A popularização do consumo de suplementos alimentares e a vulnerabilidade do consumidor. Revista $A D M . M A D E$, v. 21, n. 1, p. 34-50, jan./abr.2017. DOI: /10.21714/2237-51392017v21n1p034050.

SOUZA, L. L. F.; GERHARD, F.; BRITO, E. P. Z. Desafios na formação de profissionais em Administração no Brasil. Administração: Ensino e Pesquisa, v. 19, n. 1, p. 1-31, jan./abr. 2018. 10.13058/raep.2018. v19n1.775.

TADAJEWSKI, M. Critical Marketing Studies. In: TADAJEWSKI, M. et al. Key Concepts in Critical Management Studies. New Dehli: Sage, 2011. p. 83-87.

. Towards a history of critical marketing studies. Journal of Marketing Management, v. 26, n. 9-10, p. 773-824, Sep. 2010. DOI: 10.1080/02672571003668954.

TEKLEHAIMANOT, M. L. et al. Moving toward new horizons for marketing education: designing a marketing training for the poor in developing and emerging markets. Journal of Marketing Education, v. 39, n. 1, p. 47-60, Apr. 2017. DOI: 10.1177/0273475316688318.

TREGEAR, A. et al. Critically divided? How marketing educators perceive undergraduate programmes in the UK. European Journal of Marketing, v. 44, n. 1/2, p. 66-86, Feb. 2010. DOI: 10.1108/03090561011008619. VAN DIJK, T. A. Discurso e Poder. 2. Ed. São Paulo: Contexto, 2015. 
VASCONCELOS, M. F.; COSTA, F. J.; CARVALHO, D. T. Educação em marketing: visões e práticas de domesticação no contexto nordestino. REUNIR: Revista de Administração, Contabilidade e Sustentabilidade, v. 6, n. 1, p. 107-117, jan./abr. 2016. DOI: 10.18696/reunir.v6i1.427.

VELUDO-DE-OLIVEIRA, T.; QUINTÃO, R.; URDAN, A. Disciplinas e bibliografia no ensino de marketing nos programas de doutorado em administração no Brasil. Organizações \& Sociedade, v. 21, n. 71, p. 661-678, out./dez. 2014. DOI: 10.1590/S1984-92302014217100007.

VENKATESH, A.; PEÑALOZA, L. From marketing to market: a call for a paradigm shift. In: SHETH, J.; SISODIA, R. Does marketing need a reform? Fresh perspectives on the future. New York: M. E. Sharpe, 2006. p. 134-50.

VIANA, M. F.; COSTA, A. P.; BRITO, M. J. D. A hermenêutica crítica e estudos em marketing: aproximações e possibilidades. Organizações \& Sociedade, v. 23, n. 76, p. 92-109, jan./mar. 2016. DOI: 10.1590/1984-9230765.

VIEIRA, F. G. D. Narciso sem espelho: a publicação brasileira de marketing. Revista de Administração de Empresas, v. 43, n. 1, jan./mar. 2003. DOI: 10.1590/S0034-75902003000100009.

WILKIE, W.; MOORE, E. Macromarketing as a pillar of marketing thought. Journal of Macromarketing, v. 26, n. 2, p. 224-232, Dec. 2006. DOI: 10.1177/0276146706291067.

.; _. Scholarly research in marketing: exploring the "4 Eras" of thought development. Journal of Public Policy \& Marketing, v. 22, p. 116-146, Sep. 2003. DOI: 10.1509/jppm.22.2.116.17639.

WITKOWSKI, T. H. Antiglobal challenges to marketing in developing countries: exploring the ideological divide. Journal of Public Policy \& Marketing, v. 24, n. 1, p. 7-23, Apr. 2005. DOI: 10.1509/ jppm.24.1.7.63902.

WODAK, R.; MEYER, M. (Ed.). Methods of critical discourse studies. Sage, 2015. 272 p.

YIN, R. Pesquisa qualitativa do início ao fim. Porto Alegre: Penso, 2016. 336 p. 